\title{
Boundary layer evolution over the central Himalayas from radio wind profiler and model simulations
}

\author{
Narendra Singh ${ }^{1}$, Raman Solanki ${ }^{1,2}$, Narendra Ojha ${ }^{3}$, Ruud H. H. Janssen ${ }^{3}$, Andrea Pozzer ${ }^{3}$, and \\ Surendra K. Dhaka ${ }^{4}$ \\ ${ }^{1}$ Atmospheric Science Group, Aryabhatta Research Institute of Observational Sciences, Manora Peak, Nainital, India \\ ${ }^{2}$ Department of Physics \& Astrophysics, University of Delhi, Delhi, India \\ ${ }^{3}$ Department of Atmospheric Chemistry, Max Planck Institute for Chemistry, Mainz, Germany \\ ${ }^{4}$ Radio and Atmospheric Physics Lab., Rajdhani College, University of Delhi, Delhi, India
}

Correspondence to: Narendra Singh (narendra@ aries.res.in)

Received: 1 February 2016 - Published in Atmos. Chem. Phys. Discuss.: 11 April 2016

Revised: 9 July 2016 - Accepted: 28 July 2016 - Published: 24 August 2016

\begin{abstract}
We investigate the time evolution of the Local Boundary Layer (LBL) for the first time over a mountain ridge at Nainital $\left(79.5^{\circ} \mathrm{E}, 29.4^{\circ} \mathrm{N}, 1958 \mathrm{~m}\right.$ a.m.s.l.) in the central Himalayan region, using a radar wind profiler (RWP) during November 2011 to March 2012, as a part of the Ganges Valley Aerosol Experiment (GVAX). We restrict our analysis to clear-sunny days, resulting in a total of 78 days of observations. The standard criterion of the peak in the signalto-noise ratio $(S / N)$ profile was found to be inadequate in the characterization of mixed layer (ML) top at this site. Therefore, we implemented a criterion of $S / N>6 \mathrm{~dB}$ for the characterization of the $\mathrm{ML}$ and the resulting estimations are shown to be in agreement with radiosonde measurements over this site. The daytime average (05:00-10:00 UTC) observed boundary layer height ranges from $440 \pm 197 \mathrm{~m}$ in November (late autumn) to $766 \pm 317 \mathrm{~m}$ above ground level (a.g.l.) in March (early spring). The observations revealed a pronounced impact of mountain topography on the LBL dynamics during March, when strong winds $\left(>5.6 \mathrm{~m} \mathrm{~s}^{-1}\right)$ lead to LBL heights of $650 \mathrm{~m}$ during nighttime. The measurements are further utilized to evaluate simulations from the Weather Research and Forecasting (WRF) model. WRF simulations captured the day-to-day variations up to an extent $\left(r^{2}=0.5\right)$, as well as the mean diurnal variations (within $1 \sigma$ variability). The mean biases in the daytime average LBL height vary from $-7 \%$ (January) to $+30 \%$ (February) between model and observations, except during March $(+76 \%)$. Sensitivity simulations using a mixed layer model (MXL/MESSy) indicated that the springtime overestimation
\end{abstract}

of LBL would lead to a minor uncertainty in simulated surface ozone concentrations. However, it would lead to a significant overestimation of the dilution of black carbon aerosols at this site. Our work fills a gap in observations of local boundary layer over this complex terrain in the Himalayas, and highlights the need for year-long simultaneous measurements of boundary layer dynamics and air quality to better understand the role of lower tropospheric dynamics in pollution transport.

\section{Introduction}

Measurements on the diurnal evolution of the planetary boundary layer (PBL), the marine boundary layer (MBL), and in particular over high-altitude complex terrains the local boundary layer (LBL), are essential to understand the vertical transfer of momentum, energy and the mixing of pollutants in the lower troposphere. The depth or height of the PBL is a fundamental parameter in numerical simulations of regional meteorology and air quality. The height of the mixed layer (ML) is a measure of the effectiveness of the energy transfer from the sun to the earth's surface and thereby to the lower atmosphere and is therefore important for understanding various atmospheric processes (Stull, 1989; Garratt, 1993). Despite being simple to understand conceptually, the measurement of ML height is rather difficult (Coulter and Holdridge, 1998). The most traditional method is the analysis of potential temperature and specific humidity pro- 
files, which are obtained from radiosonde ascents (Hooper and Eloranta, 1986). However, in the past 3 decades several remote-sensing devices such as the light detection and ranging (lidar), sound detection and ranging (SoDAR), radio acoustic sounding system (RASS), GPS occultation measurements (Basha and Ratnam, 2009; F. Xie et al., 2012) and radio wind profilers (RWP) have become indispensable tools to probe the atmospheric boundary layer and the troposphere within the first few kilometers above the ground. A review and detailed studies carried out earlier on PBL evolution over various locations are given elsewhere (Friehe, 1987; Garratt and Taylor, 1996).

It is essential to mention that most of the studies cited here and the references therein are confined to mid and highlatitude regions, and that very few efforts have been made to characterize the PBL evolution over the Indian subcontinent and the complex terrain of the Himalayan region. The available studies using satellite and ground-based measurements over the Indian region have shown influences of the boundary layer evolution and associated mixing on the trapping, dispersion, and transport of pollutants upwards to the pristine high-altitude locations. Some of these studies are connoted subsequently.

The variations in boundary layer height are suggested to influence the dispersion of air pollutants near the earth surface (Guatam et al., 2007). Deeper boundary layers could also mix residual layer air with higher ozone concentrations with the air mass near the surface (Reddy et al., 2012). The investigation of local boundary layer evolution and associated mixing is additionally important over the pristine Himalayas located just north to the densely populated and polluted Indo-Gangetic Plain (IGP) in order to understand the role of regional pollution on the air quality above the Himalayas (Sarangi et al., 2014). In previous studies, the convective mixing of photochemical pollution (Ojha et al., 2012) and the potential influence of distantly transported and IGP aerosol emissions, on air quality in the central Himalayas has been demonstrated (Solanki et al., 2013; Solanki and Singh, 2014) with the measurements over the region. Continuous measurements of LBL evolution and mixing have not been available until a recent intensive field campaign "Ganges Valley Aerosol Experiment (GVAX)" (Kotamarthi, 2010; Kotamarthi and Satheesh, 2011; Manohanarn et al., 2014). However, systematic and high-resolution measurements of the PBL evolution over the IGP region and the LBL evolution over the Himalayan region for a complete seasonal cycle are still missing.

During the GVAX campaign at ARIES, Nainital regular radiosonde launches (four per day) were made, but a clear picture of LBL or ML evolution was not possible since four radiosonde profiles a day provided only snapshots of the atmosphere. On the other hand, for the first time, RWP was operated for wind measurements and can also be utilized to derive an estimate of boundary layer height (Angevine et al., 1994; Coulter and Holdridge, 1998) with a finer temporal resolution (15 min). Therefore, the RWP is the best possible tool to determine ML evolution over the site. The RWP also gives a deep insight into the vertical structure of the boundary layer in general, which is crucial in understanding dynamic meteorology, pollutant transport and dispersion (B. Xie et al., 2012). Studies on ABL dynamics over complex terrain have been made by Reddy et al. (2006) and Kalapureddy et al. (2007) over a moderately hilly terrain in Gadanki valley region in Southern India. However, no such studies have been made over the Himalayas for the highly contrasting winter and spring seasons. The importance of this study can be understood by the fact that a strong diurnal cycle can appear in the LBL or ML over hilly terrain during the fair-weather conditions (Reddy et al., 2002).

The main objectives of our study are the following:

1. To investigate the diurnal, and monthly variations in LBL evolution over the central Himalayas using RWP observations.

2. To evaluate boundary layer height with regional model (WRF) simulations, by using a setup similar to the one evaluated and extensively used over the Indian region (e.g., Kumar et al., 2012a, b; Sarangi et al., 2014; Ojha et al., 2016).

3. To assess the influence of model uncertainties in boundary layer height on air quality simulations, by conducting sensitivity runs with a mixed layer model (MXL/MESSy).

In this study we implemented a new criterion for the $S / N$ that captures nearly systematic feature of LBL evolution with time, since above a mountain peak, the structure of the LBL is not as prominent as that observed over high pressure regions or flat terrain. The ML height estimation method using the RWP has been validated with ML heights from radiosonde profiles. We investigate the mean diurnal variations of ML height during months covering the late autumn (November), winter (December-January-February) and early spring (March). The impact of mountain topography on LBL evolution in the presence of strong winds during nighttime is also investigated. Finally, we compare the dayto-day and diurnal variations in LBL height deduced from RWP measurements with simulations from a regional model (WRF). The implications of model-observation biases on air quality studies are also discussed.

The manuscript begins with a brief description of the observational site, the RWP instrumentation and the mixed layer determination methodology in Sect. 2. The Weather Research and Forecasting (WRF) model that is employed to simulate the temporal variations in boundary layer height and the mixed layer model (MXL/MESSy) that is used for sensitivity simulations of air quality are described in Sect. 3. The results and discussion are presented in Sect. 4, followed by the summary and key conclusions in Sect. 5. 


\section{Observational site and methodology}

\subsection{Observational site}

The observational site is located at a mountain top called Manora Peak ( $79.5^{\circ} \mathrm{E}, 29.4^{\circ} \mathrm{N}$ and $1958 \mathrm{~m}$ a.m.s.l.), near Nainital, a high-altitude station in the central Himalayas. The observational site has $600 \mathrm{~m}$ deep valleys on the eastern and western sides and the valley axes are aligned approximately in the SE and SW direction, respectively. To the north of the peak the topography is very craggy and rising; towards the south, the mountains are gradually sloping into the adjacent plains of Haldwani. The mountain peak has a slope of approximately $25^{\circ}$ on the eastern and western side, and is covered with a dense forest on all sides, consisting mainly of trees and shrubs. All measurements presented in this study were made on the mountain peak with no obstructions such as buildings or trees in any direction. The site (Sagar et al., 2004) has been the subject of intensive studies on synoptic wind patterns and trace gases (Sarangi et al., 2014), balloon soundings (Ojha et al., 2014) and aerosol extinction profiles (Solanki and Singh, 2014). A detailed overview of the measurement site and the atmospheric science research conducted there has been provided in a recent review paper (Sagar et al., 2015).

\subsection{RWP instrumentation and mixed layer determination}

Wind profilers are basically designed to make the continuous measurements of wind components, i.e., zonal meridional and vertical, at very fine temporal and spatial resolution in all weather conditions. These profilers generally operate at various frequencies (30-3000 MHz) depending upon the science objectives. Such a wind profiler developed by DeTect, Inc., which operates at $1290 \mathrm{MHz}$ was utilized at the observational site. The system is capable of changing the beam pointing angle on a pulse-by-pulse basis for five beam positions, and provided the backscattered signal and the wind profiles between 0.1 and $6 \mathrm{~km}$. The profiler collected a sample every $30 \mathrm{~s}$, completing a cycle of all five beam positions every $150 \mathrm{~s}$. By selecting a beam elevation of $90^{\circ}, S / N$ profiles from the vertical beam were only incorporated in this analysis. The $S / N$ data for the vertical beam are available with a resolution of $62.6 \mathrm{~m}$, with the first range bin at $124 \mathrm{~m}$.

The ML height is inferred from the signal-to-noise ratio $(S / N)$ recorded by the RWP. The underlying theory has been discussed by White et al. (1991a, b). The principal source of scattered signal to RWP is moisture, which is the primary constituent of inhomogeneity in the radio refractive index of the air. These wind profilers basically detect the fluctuations in radio refractive index caused by vertical humidity and temperature gradients. These inhomogeneities are characterized by the refractive index structure parameter $C_{n}^{2}$ (Tatarskii, 1971; Green et al., 1979; Gossard et al., 1982; Gage, 1990;
Raghavan, 2003; Singh et al., 2008). The profiler $S / N$ at a given range is directly proportional to $C_{n}^{2}$ (Ottersten, 1969).

The vertical structure of the PBL (with height $Z_{i}$ ) consists of three different layers (Angevine et al., 1994). The first layer is the surface layer starting from ground to $0.1\left(Z_{i}\right)$, the second layer is the ML extending from $0.1 Z_{i}$ to $0.8 Z_{i}$ and the third layer is the entrainment zone from $0.8\left(Z_{i}\right)$ to $1.2\left(Z_{i}\right)$. Above the PBL is the free troposphere. Generally, over a plain site the top of the ML is characterized by increased turbulence, and strong temperature and moisture gradients, which are represented by a peak in the $S / N$ profile, marking the top of the ML (Simpson et al., 2007). However, this study is carried out over a high-altitude site ( $2 \mathrm{~km}$ a.m.s.l.) and because of the lack of prominent features over the mountainous site the general methods of ML height determination over plains cannot be directly applied. The complex mountainous topography generates its own LBL (e.g., Kossmann et al., 1998), which is different from the PBL in some aspects. One of those is that the $S / N$ profile, instead of exhibiting a peak in the profile, shows a gradual decrease with altitude, as depicted in Fig. 1; although at another high-altitude research station Kleine Scheidegg (Ketterer et al., 2014) a prominent peak in the $S / N$ profile was always measured in convective state of boundary layer. It may however be noted that the station at Kleine Scheidegg is situated on a mountain pass, whereas the measurements presented in this study were taken over a mountain peak; hence difference in characteristics of LBL could be anticipated due to differences in the topography. One possible explanation for this aspect of the LBL could be the difference in the characteristics of entrainment zone over plains and mountainous terrain, since the entrainment zones basically form between the tops of highest thermal plumes and deepest part of the sinking dry air penetrating through the free troposphere. In contrast to a flat terrain, mountainous or complex terrain may not have that prominent formation of the entrainment zones due to complex topography, as convective mixing over the ridge may be influenced by slope winds and occasional strong horizontal flows. Therefore, in this study we have considered the region of $S / N>6$ decibels (dB) as the LBL over the site and validated this method by comparing the results with those deduced from the vertical profiles of potential temperature and specific humidity from radiosonde (Vaisala RS92-SGP) ascents. In case of RWP $S / N$ profiles showing multiple transitions across the $6 \mathrm{~dB}$ threshold, the maximum altitude was selected as the ML height, as shown by the 10:00 UTC profile in Fig. 1. Although averaging time of $30 \mathrm{~min}$ is considered for parameters determining the evolution of PBL, but for the LBL study over the site we have considered the averaging time of 15 min (for mean $S / N$ profiles) for better statistical average and taking into the mixing timescale, since the LBL is in a much more dynamical state, i.e., considering the convective mixing and the topographic effects, as compared to PBL. The contour plots of $S / N$ were also analyzed visually in order to confirm the reliability of the ML height estima- 


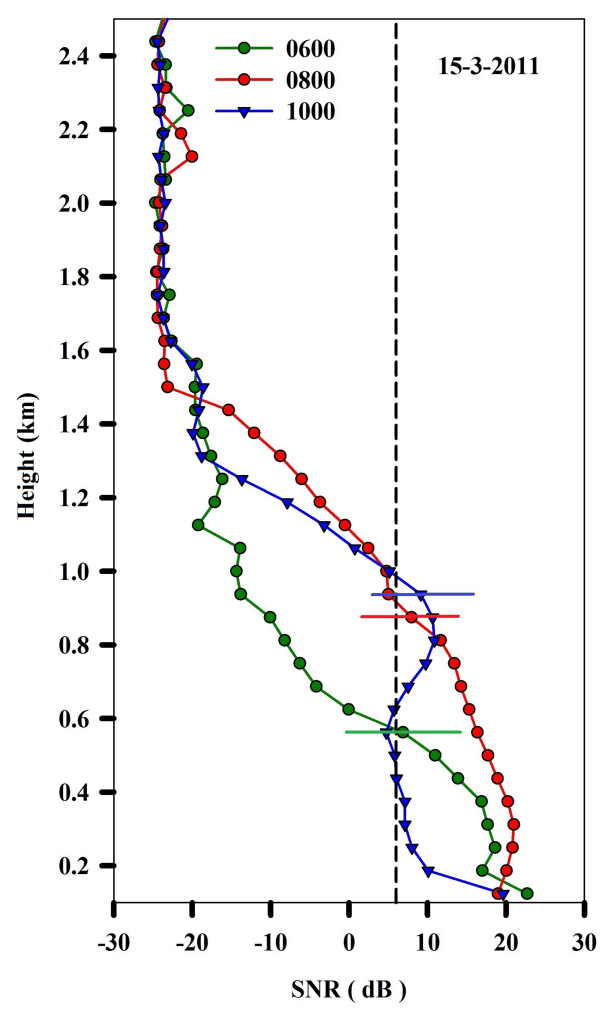

Figure 1. The signal-to-noise ratio profiles (15 min averaged) on 15 March 2012 during the peak sunshine hours. The estimated mixed layer height for each profile is marked by the horizontal bar.

tions at the $6 \mathrm{~dB}$ threshold. However, the $S / N$ is proportional to refractive index structure parameters, hence can further be subjected to derive reflectivity and the turbulence parameters that again are the tracers of LBL or PBL evolution.

In order to determine the ML height from radiosonde measurements and thus authenticate the $6 \mathrm{~dB}$ criterion, the bulk Richardson method, specific humidity gradient (maxima), and virtual potential temperature profiles gradient method were tested; but as expected over a complex terrain, only the specific humidity gradient (maxima) method provided promising results. A detailed correlation analysis was done for ML derived from specific humidity gradient method vs RWP ( $S / N$ method) and the maximum correlation $\left(r^{2}=\right.$ 0.70 ) between the two is found to be at the $S / N$ value of $6 \mathrm{~dB}$, for the noon-time and evening (06:00 and 12:00 UTC) profiles that closely correspond to the convective state of boundary layer over the site. For the analysis, the cases of minimum ML height estimation from RWP (RWP starts measurements beyond $124 \mathrm{~m}$ in the vertical) and radiosonde, as well as days of very weak $\left(<10 \mathrm{~g} \mathrm{~kg}^{-1} \mathrm{~km}^{-1}\right)$ gradient in specific humidity profiles were discarded.

The agreement between radiosonde and RWP estimated ML height for midnight and early morning profiles (18:00 and 00:00 UTC) turns out to be very poor for all of the known methods. The disagreement can be attributed to the topog- raphy of the site (a mountain peak) and the drift in the radiosonde, which thus provides measurements of ML height over the adjoining valleys or ridges at nighttime. Since the ML top follows the topography over mountainous terrain, and the degree to which ML top follows the topography is minimum at noontime and afternoon hours (De Wekker and Kossmann, 2015). Hence, a higher correlation between radiosonde ML height estimation and RWP derived LBL height is certainly expected to be significant only during the noontime to evening hours.

The vertical profiles of meteorological parameters obtained from the radiosonde ascents are also utilized to provide the vertical structure of the atmosphere for comparison with RWP measurements. The hourly wind speed observations made through a collocated automatic weather station (AWS) over the site are also incorporated to understand the state of the surface layer over the site.

\section{Model simulations}

\subsection{Weather research and forecasting (WRF) model}

This study uses the version 3.5.1 of the Weather Research and Forecasting (WRF) model to simulate the temporal variations of boundary layer height at Nainital during the study period. Meteorological fields from NCEP Final Analysis (FNL) data available at the spatial resolution of $1^{\circ}$ and temporal resolution of $6 \mathrm{~h}$ has been used to provide the initial conditions and the lateral boundary conditions in the model. Simulations were performed for two different spatial resolutions. The simulations from the coarser domain $(15 \mathrm{~km} \times 15 \mathrm{~km})$ were used to provide the initial and boundary conditions for the higher resolution domain $(5 \mathrm{~km} \times 5 \mathrm{~km})$. Both model domains and the topography of this region are shown in Fig. 2. The errors in the simulated meteorology in the coarser domain were limited by nudging of the temperature, water vapor and horizontal winds with a nudging coefficient of $6 \times 10^{-4}$ per second at all the vertical levels (Kumar et al., 2012a, b; Ojha et al., 2016).

The cloud microphysics was represented by the Thompson microphysics scheme (Thompson et al., 2008). The longwave radiation has been calculated using the rapid radiative transfer model (RRTM) (Mlawer et al., 1997) and shortwave radiation is calculated using the Goddard shortwave scheme (Chou and Suarez, 1994). The surface layer has been parameterized using the Monin-Obukhov scheme (Janjic, 1996). The Noah Land Surface Model, which utilizes the Unified NCEP/NCAR/AFWA scheme with soil temperature and moisture in four layers, has been used to parameterize the land surface processes (Chen and Dudhia, 2001). The planetary boundary layer dynamics were parameterized using the Eta operational Mellor-Yamada-Janjic (MYJ) scheme, which is based on a one-dimensional prognostic Turbulent Kinetic Energy (TKE) scheme with local vertical mixing 
(a) $15 \mathrm{~km} \times 15 \mathrm{~km}$

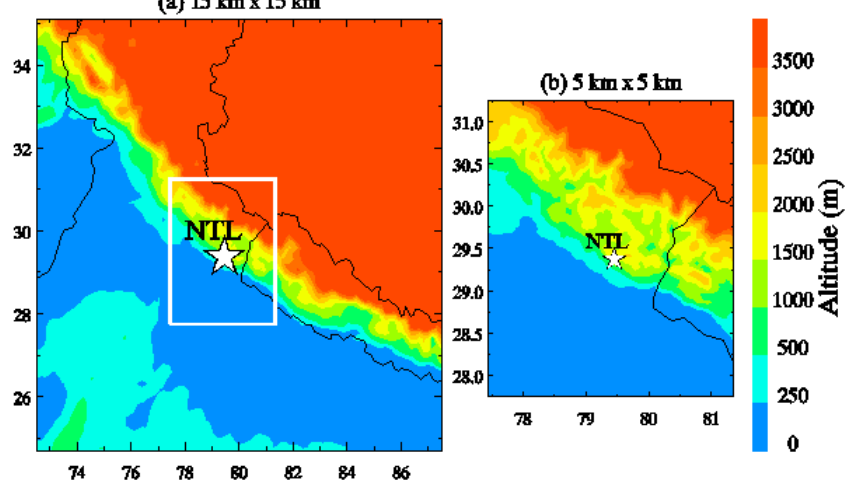

Figure 2. The WRF simulation domains used in the study are shown. The coarser domain $(15 \mathrm{~km} \times 15 \mathrm{~km})$ simulations are used to drive the simulation over the nested domain shown as white box in panel (a) and separately in panel (b). The geographical topography of the region and the location of measurement site Nainital (NTL) are also shown.

(Janjic, 2002). The cumulus parameterization was based on the new Grell (G3) scheme for the coarser domain, while it has been turned off for the nested domain as shown in the Supplement (Fig. S1). Detailed discussions on simulations using the WRF model, the chosen physics options and meteorological nudging, including evaluations over the Indian region, can be found in recent studies (Kumar et al., 2012a, b; Sarangi et al., 2014; Ojha et al., 2016). Hourly model output from the nested $5 \mathrm{~km} \times 5 \mathrm{~km}$ simulation has been used in the analysis.

\subsection{Mixed layer model (MXL/MESSy)}

The implications of biases in the WRF simulated boundary layer dynamics, as compared to RWP measurements, on air quality simulations have been investigated by conducting sensitivity simulations with the MiXed Layer/Modular Earth Submodel System model (MXL/MESSy, version 1.0; Janssen and Pozzer, 2015). Although the BL dynamics are represented in a different way in MXL/MESSy than in WRF, we can use the former to obtain an insight into the effects of an overestimation of BL height on modeled chemical species concentrations. MXL/MESSy has been developed recently as a column model in the MESSy framework (Jöckel et al., 2010). Within MXL/MESSy, the MXL submodel accounts for the dynamics of the convective boundary layer during daytime, by explicitly calculating BL-free troposphere exchange of scalars and chemical species through entrainment. Through the coupling of MXL with other MESSy submodels for processes that are relevant for atmospheric chemistry, MXL/MESSy can be used to evaluate the influence of BL dynamics on atmospheric chemistry. The mixed layer theory states that under convective conditions, strong turbulent flow causes perfect mixing of quantities over the entire depth of the ABL (Vilà-Guerau de Arellano et al., 2015). There- fore, scalars and reactants in the convective boundary layer are characterized by a well-mixed vertical profile over the whole depth of the ABL. In MXL, the transition between the well-mixed BL and the free troposphere is marked by an infinitesimally thin inversion layer. In this study, chemical transformations are represented by the Mainz Isoprene Mechanism 2 (MIM2; Taraborrelli et al., 2009). Black Carbon (BC) is treated as a passive tracer, which is appropriate at the short timescale $(6 \mathrm{~h})$ of our simulations.

\section{Results and discussion}

\subsection{Estimation of ML height}

Figures 3 and 4 depict the diurnal variability $(24 \mathrm{~h}$ cycle) of the RWP measured $S / N$ profiles (15 min averaged) on two contrasting representative days in different months (with sensible heat flux of 17 and $50 \mathrm{~W} \mathrm{~m}^{-2}$ during December and March). For each day, data from four radiosonde launches (approximate launch time of 00:00, 06:00, 12:00 and 18:00 UTC) were also available, which are used to investigate the profiles of potential temperature and specific humidity for comparison with ML height estimated from the RWP. A very clear smooth diurnal variation in $S / N$ is observed on 17 December 2011, as illustrated in Fig. 3; this feature is characteristic of a mountain LBL in the winter under calm wind conditions (wind speed $<2 \mathrm{~m} \mathrm{~s}^{-1}$ ), the evolution is seen from 02:00 to 13:00 UTC, i.e., 07:30 to 18:30 h local time $(\mathrm{LT}=\mathrm{UTC}+5.5 \mathrm{~h})$, attaining a peak of $500 \mathrm{~m}$ at noon (07:00 to 08:00 UTC). During nighttime (13:00 to 02:00 UTC) the LBL is extremely shallow in depth, and under the RWP lower detection range (i.e., $124 \mathrm{~m}$ ). The specific humidity and potential temperature profiles also show a clear demarcation between the LBL and the free troposphere during daytime (06:22 UTC), and the height of the inversion $(\sim 300 \mathrm{~m})$ agrees quite well with the RWP-derived LBL height at the same time. The other radiosonde profiles (23:50, 11:48 and 17:41 UTC) show stable potential temperature profiles, which is consistent with a stable (nocturnal) boundary layer.

Figure 4 shows the ML height evolution on 15 March 2012, which is considered as representative of the early spring season over the site, based on the mean diurnal variability of the ML during March. Two distinct growth phases of the ML are observed during the $24 \mathrm{~h}$ cycle, with one starting at 05:00 UTC and the other at 13:00 UTC. The growth and decay in ML from 05:00 to 12:00 UTC is consistent with the diurnal cycle of incoming solar radiation. The peak height of the ML is above $900 \mathrm{~m}$, and attained from 08:00 to 10:00 UTC. A second growth phase in the ML depth starts from 13:00 UTC, and the ML remains stable from 15:00 to 20:30 UTC with ML height reaching up to approximately $700 \mathrm{~m}$. The minimum ML height of $300 \mathrm{~m}$ is observed from 00:00 to 03:30 UTC. The vertical profile of specific humid- 

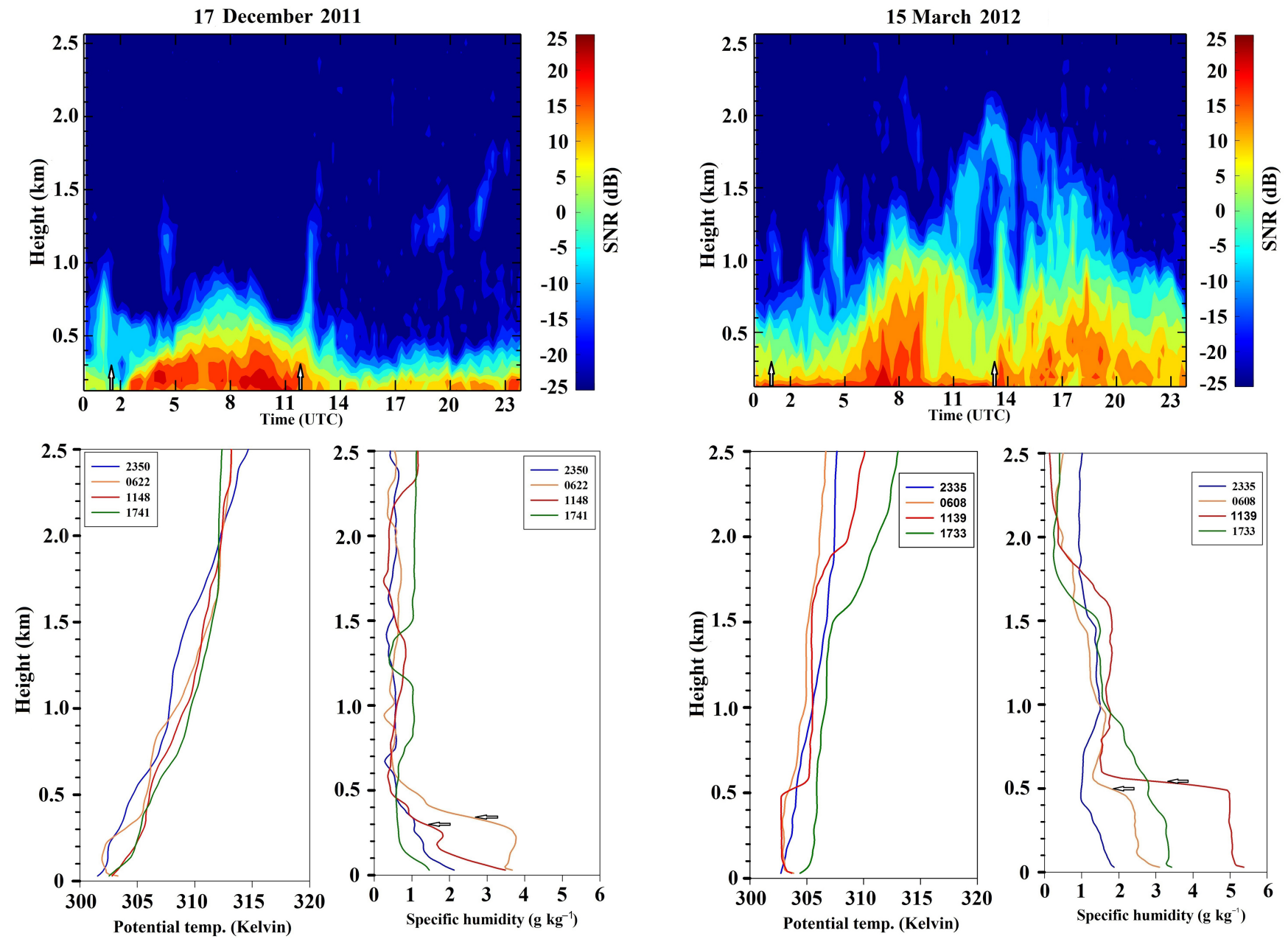

Figure 3. Mixed layer height for 17 December 2011. The upper panel shows range time intensity (RTI) plot of $S / N$ (15 min averaged) measured with RWP, the vertical arrows indicate the time of sunrise and sunset. The lower panel shows the vertical profiles of potential temperature and specific humidity (horizontal arrows indicate the ML height estimated with specific humidity gradient maxima method) derived from the four radiosonde flights conducted during the day (marked with different colors).

ity shows a strong inversion between 500 to $550 \mathrm{~m}$, which is consistent with the estimated ML height derived from the RWP at the respective radiosonde launching time (06:08 and 11:39 UTC). However, a clear inversion in the potential temperature profile is seen only for the 11:39 UTC ascent and a very weak gradient is also seen for the 06:08 UTC profile, for both profiles the inversion occurs at approximately $500 \mathrm{~m}$ pointing at a convective ABL. It is also notable from 11:39 and 17:33 UTC radiosonde launches, that inversion in the potential temperatures and specific humidity are taking place between 1500 and $2000 \mathrm{~m}$ which could be due to advected residual layers.

Figure 4. Same as Fig. 3 but for 15 March 2012.

\subsection{Diurnal variations}

The comparison of monthly average diurnal variations in the ML height during the period from November 2011 to March 2012 is presented in Fig. 5. The ML height was estimated only for the clear sunny days (without any large mesoscale activity), which were selected for each month through the sky condition log book that is maintained at the site and also by the visual inspection of sky camera videos. Table 1 shows the number of clear sky days for the different months.

A clearly defined diurnal variation in ML height is observed from November to February with minimum amplitudes during November and December, exhibiting a peak value of $500 \mathrm{~m}$ from 07:00 to 09:00 UTC. From January to March, the mean ML height shows overall a gradual increase, with peak values above $800 \mathrm{~m}$. In general, the nocturnal boundary layer height remains below $300 \mathrm{~m}$ from 16:00 to 01:00 UTC. Towards the start of spring in the month of March, the ML height shows a distinct behavior with a mix- 


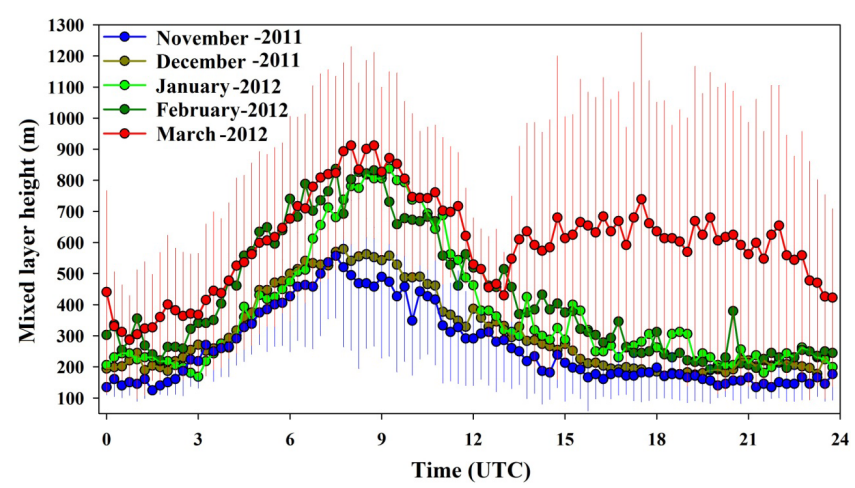

Figure 5. Monthly averaged mixed layer height determined from 15 min averaged $S / N$ profiles, measured with RWP. For the sake of clarity, variability is only shown for November and March months.

Table 1. RWP data set used for studying the mixed layer height evolution.

\begin{tabular}{lrr}
\hline Month & Total no. of days & Clears sky days \\
\hline November 2011 & 16 & 12 \\
December 2011 & 31 & 26 \\
January 2012 & 31 & 10 \\
February 2012 & 29 & 13 \\
March 2012 & 31 & 17 \\
\hline
\end{tabular}

ing depth as high as $650 \mathrm{~m}$ during 14:00 to 22:00 UTC, which is attributed to the strong horizontal flow hitting the mountain (discussed in Sect. 4.3), which gives rise to the lifting motions, and hence the rise of a few $100 \mathrm{~m}$ in the mixing depth.

\subsection{Impact of mountain topography}

The impact of mountain topography on LBL dynamics can be clearly identified by comparing the diurnal variability of the ML height in December and March. Figure 6 shows the diurnal variability in wind speed during December 2011 and March 2012 measured by a collocated AWS at the site. In December, when the winds are calm $\left(<2-3 \mathrm{~m} \mathrm{~s}^{-1}\right)$, the LBL growth starts around 03:00 UTC. From then onwards, the ML height increases gradually and approaches a maximum of about $700 \mathrm{~m}$ in the afternoon, which appears to be in phase with the intensity of sunshine. ML height drops after 10:00 UTC, and in the evening from 13:00 UTC onward stays unchanged during the nighttime (15:00 to 03:00 UTC). However, in March when the wind speeds are more than doubled, reaching values as high as $6 \pm 3 \mathrm{~m} \mathrm{~s}^{-1}$, the LBL settling in nighttime hours is hindered since such high winds cause significant wind shear, thereby generating turbulent eddies and increasing the vertical mixing of surface-layer air (Solanki et al., 2016), leading to a second growth and decay phase in LBL depth from 13:00 to 23:30 UTC. This second growth phase can also be understood as the deepening

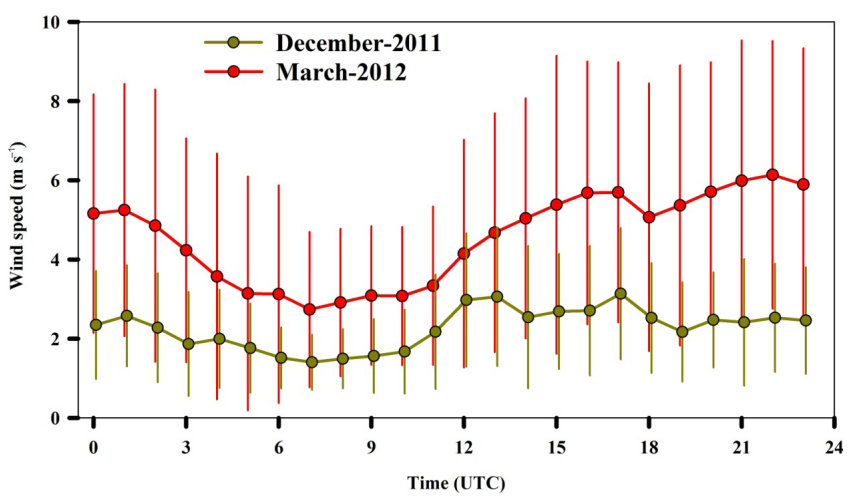

Figure 6. The monthly average diurnal variation in surface wind speed over the site during the clear sky days, selected for estimation of the mixed layer height as depicted in Fig. 3.

of surface layer, transforming into residual layer (Henne et al., 2014). A decrease in wind speed is not observed from 23:00 to 03:00 UTC when the LBL decreases in depth, this could be attributed to the cooling of the surface beyond a certain extent, leading to the formation of a thin stable nocturnal boundary layer decoupled from the residual layer above. High wind speeds near the surface are one of the characteristics of such stable layers.

\subsection{Comparison with model simulations}

In this section, we utilize the ML height observations from the RWP to evaluate the simulation from a regional model (WRF) that has been used in previous studies for simulating the meteorology and regional air quality over Indian region (e.g., Kumar et al., 2012a, b; Sarangi et al., 2014; Ojha et al., 2016). We focus on the capability of the model, with a setup similar to the one used in aforementioned studies, in capturing the diurnal and day-to-day variability in mixing depth. Errors in simulating the mixing depth variations could lead to considerable uncertainties in the dispersion and mixing of the air pollutants over this region. For comparison, the model output has been obtained for the same selected clear-sunny days as the RWP measurements. Since WRF output is instantaneous hourly data, instantaneous hourly data have also been used from the RWP for comparison.

Figure 7a shows the comparison of daytime (05:0010:00 UTC) average boundary layer height from RWP measurements and WRF simulations from November 2011 to March 2012. The day-to-day variations in the daytime boundary layer height, as observed from the RWP, are captured by the model during late-autumn and throughout winter; however, the model shows significantly higher boundary layers towards the start of the spring (March). Figure 7b shows a correlation analysis between model simulations and observations of daytime boundary layer height. Overall the model and observations are in reasonable agreement during the study period $\left(r^{2}=0.5\right)$. The monthly statistics of the 
Table 2. Daytime (05:00-10:00 UTC) monthly mean and percentage bias between RWP measurements and WRF simulations.

\begin{tabular}{lrrrr}
\hline Month & Observational mean $(\mathrm{m})$ & Model mean $(\mathrm{m})$ & Mean bias $(\mathrm{m})$ & Percent bias $(\%)$ \\
\hline November 2011 & $440 \pm 197$ & $381 \pm 90$ & -59 & -13.4 \\
December 2011 & $500 \pm 245$ & $415 \pm 112$ & -85 & -17 \\
January 2012 & $624 \pm 289$ & $577 \pm 149$ & -47 & -7.5 \\
February 2012 & $686 \pm 268$ & $890 \pm 439$ & +204 & +29.7 \\
March 2012 & $766 \pm 317$ & $1350 \pm 664$ & +584 & +76.2 \\
\hline
\end{tabular}
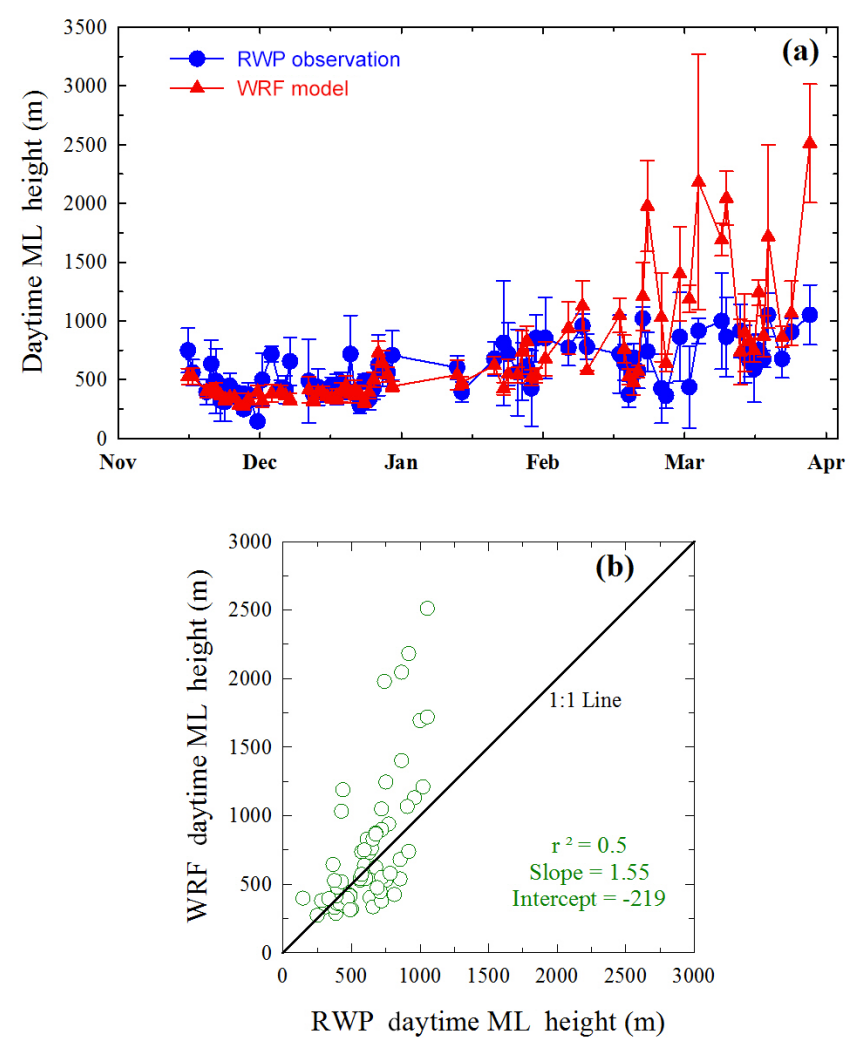

Figure 7. (a) A comparison of daytime (05:00-10:00 UTC) average boundary layer height from RWP measurements and WRF simulations at Nainital during the study period. Error bars represent $1 \sigma$ standard deviation during daytime. (b) Correlation analysis between observational and model daytime boundary layer height. A $1: 1$ line is also shown.

model observation comparison are given in the Table 2. The mean bias is the average difference (WRF - RWP) for the selected days of each month, and similarly the percentage bias is the percentage difference (WRF - RWP) normalized with respect to the mean RWP measurements.

On average, the noontime boundary layer height is slightly underestimated from November to January, by 47 to $85 \mathrm{~m}$ (7$17 \%)$. The variability ( $1 \sigma$ standard deviation) in the modeled boundary layer height is also lower $(90-149 \mathrm{~m})$ than in the observations (197-289 m) during this period. However, during the transition from winter to spring (February), the vari- ability and biases are observed to change. The model overestimates the boundary layer height by $204 \mathrm{~m} \mathrm{(30 \% )} \mathrm{and} \mathrm{shows}$ higher variability $(439 \mathrm{~m})$ than the observations $(268 \mathrm{~m})$, in contrast to the months of November-January. Model is seen to overestimate the daytime mean boundary layer height significantly (Table 2) during March (by $76.2 \%$ ), and the variability in the modeled boundary layer height is also seen to be more than that in the observations $(317 \mathrm{~m})$.

The mean diurnal variations in boundary layer height are compared between model and observations for all the months of the study period (Fig. 8). The model simulated diurnal variations are in agreement with the measurements, as average daytime as well as nighttime values are generally within $1 \sigma$ variation of each other. An appreciable disagreement between model and measurements is only seen towards the evening hours (10:00 to 12:00 UTC), when the boundary layer height shows a gradual decrease in the RWP measurements, whereas the model simulations exhibit a rapid decrease in the boundary layer height. In contrast to the period from November to February, the boundary layer height is overestimated throughout the day in March, with noontime mixing layer depth about two times higher than in the observations (Table 2 ). The overestimation of the noontime mixing layer depth by the model could be associated with the parameterization of boundary layer and land surface processes, uncertainties and/or errors in simulating other meteorological variables, in addition to the effects of unresolved geographical topography. The effects of these uncertainties could become more prominent during the spring and/or pre-monsoon due to intense solar radiation causing stronger boundary layer mixing, as compared to winter and autumn (Ojha et al., 2012; Sarangi et al., 2014). We suggest that a mixing layer depth about two times higher than in the measurements could lead to significant dilution or lead to additional entrainment when used in air quality models. In the next subsection, we explore the possible implication of model biases in March above this site on air quality simulations using a 1-D mixed layer model.

\subsection{Effects of boundary layer height overestimation on air quality simulations}

In this section, we use MXL/MESSy (Sect. 3.2) to investigate the influences of uncertainties in boundary layer height simulated by regional models on air quality simulations. For this purpose, we combined the effects of the boundary layer 


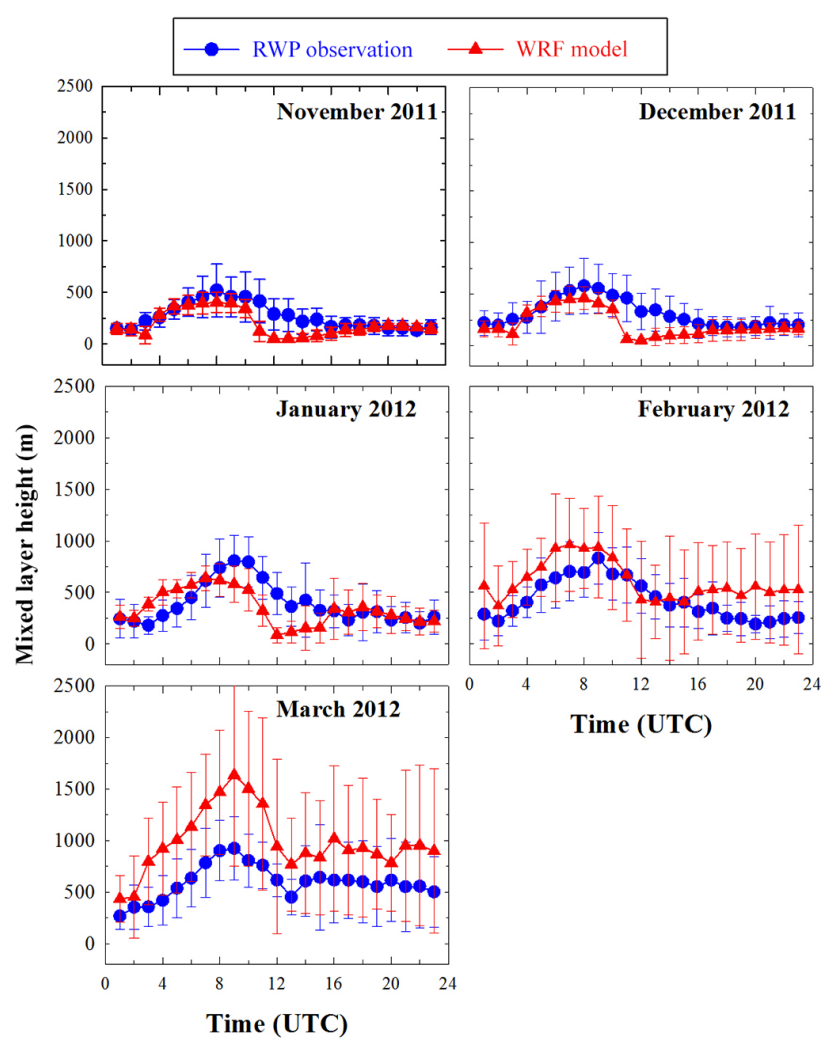

Figure 8. Comparison of the monthly averaged diurnal variations in the boundary layer height determined from RWP measurements and WRF simulations at Nainital during the study period.

overestimation during March with the available information on vertical gradients and emissions at Nainital to assess the impact on two chemical tracers: Ozone $\left(\mathrm{O}_{3}\right)$ and Black Carbon (BC).

First, we set up MXL/MESSy to reproduce the observations of boundary layer height, potential temperature, specific humidity and wind speed (Supplement, Fig. S3) for the representative day of 15 March 2012. Heat fluxes were prescribed to the model using typical values for March, based on our observations at this site using sonic anemometer measurements (Solanki et al., 2016). Initial and boundary layer conditions are given in Table 3. A set of simulations was performed (Fig. 9) to identify the simulation that reproduces the observations best, which show a rapid boundary layer growth in the morning and the simultaneous increase of potential temperature and specific moisture. In addition to the surface fluxes of sensible and latent heat, which are the main drivers of boundary layer growth, large-scale subsidence and advection of cool and moist air were required to reproduce the observations. The assumption of large-scale subsidence in MXL/MESSy is consistent with the vertical downward wind speed of a few $\mathrm{cm} \mathrm{s}^{-1}$ in the WRF simulations over the region.
Table 3. The initial and boundary conditions in the atmospheric boundary layer (ABL) and free troposphere (FT) as used in MXL/MESSy. All initial conditions are imposed at 03:00 UTC. $t$ is the time elapsed since the start of the simulation $(s)$ and $t_{d}$ the length of the simulation $(s)$. The subscripts $s$ and e indicate values at the surface and the entrainment zone, respectively.

\begin{tabular}{|c|c|}
\hline Property & Value \\
\hline $\begin{array}{l}\text { Initial ABL height } \\
h(\mathrm{~m})\end{array}$ & 280 \\
\hline $\begin{array}{l}\text { Subsidence rate } \\
\qquad \omega\left(\mathrm{s}^{-1}\right)\end{array}$ & $2 \times 10^{-5}$ \\
\hline $\begin{array}{l}\text { Surface sensible heat flux } \\
\qquad w^{\prime} \theta_{\mathrm{S}}^{\prime}\left(\mathrm{K} \mathrm{m} \mathrm{s}^{-1}\right)\end{array}$ & $0.24 \sin \left(\pi t / t_{d}\right)$ \\
\hline $\begin{array}{l}\text { Entrainment/surface heat flux ratio } \\
\qquad \beta=w^{\prime} \theta_{\mathrm{e}}^{\prime} / w^{\prime} \theta_{\mathrm{s}}^{\prime} \text { (dimensionless) }\end{array}$ & 0.2 \\
\hline $\begin{array}{l}\text { Initial ABL potential temperature } \\
\quad<\theta>(\mathrm{K})\end{array}$ & 303.8 \\
\hline $\begin{array}{l}\text { Initial FT potential temperature } \\
\qquad<\theta>_{\mathrm{FT}}(\mathrm{K})\end{array}$ & 304.0 \\
\hline $\begin{array}{l}\text { Potential temperature lapse rate FT } \\
\quad \gamma_{\theta}\left(\mathrm{K} \mathrm{m}^{-1}\right)\end{array}$ & 0.0065 \\
\hline $\begin{array}{l}\text { Surface latent heat flux } \\
\qquad w^{\prime} q_{\mathrm{s}}^{\prime}\left(\mathrm{g} \mathrm{kg}^{-1} \mathrm{~m} \mathrm{~s}^{-1}\right)\end{array}$ & $0.11 \sin \left(\pi t / t_{d}\right)$ \\
\hline $\begin{array}{l}\text { Initial ABL specific humidity } \\
\quad<q>\left(\mathrm{g} \mathrm{kg}^{-1}\right)\end{array}$ & 2.0 \\
\hline $\begin{array}{l}\text { Initial FT specific humidity } \\
\qquad q_{\mathrm{FT}}\left(\mathrm{g} \mathrm{kg}^{-1}\right)\end{array}$ & 1.9 \\
\hline $\begin{array}{l}\text { Specific humidity lapse rate FT } \\
\quad q\left(\mathrm{~g} \mathrm{~kg}^{-1} \mathrm{~m}^{-1}\right)\end{array}$ & -0.0010 \\
\hline
\end{tabular}

Figure 9 shows the results from 4 simulations. The simulation which is closest to the observations (CTRL) includes both large-scale subsidence and advection of cool and moist air. The simulation without any subsidence leads to an overestimation (by $\sim 250 \mathrm{~m}$ ) of the maximum boundary layer height. The third simulation, in which there is no advection, overestimates LBL height and temperature and underestimates specific moisture. The final simulation, without advection and subsidence, yields an overestimation of the LBL height by $400 \mathrm{~m}$.

The ozone gradient between the boundary layer and free troposphere is assumed to be $5 \mathrm{ppbv}$, as reported for the spring (MAM) season over this site based on ozonesonde observations (Ojha et al., 2014). Further, ozone-poor air is transported upwards from the valley during daytime (Ojha et al., 2012; Sarangi et al., 2014). MXL/MESSy consists of two boxes and cannot explicitly account for upslope flows. Therefore, we mimic its effect by assuming a constant ozone loss at the bottom of the lowest box. The effect of variations in the boundary layer height on $\mathrm{O}_{3}$ concentrations is found to be relatively small for the different simulations. The ozone mixing ratios differ by less than $2 \mathrm{ppb}$ when the maximum boundary layer height is $\sim 1350 \mathrm{~m}$, as compared to the more realistic $\sim 1000 \mathrm{~m}$. This is due to the relatively small gradi- 


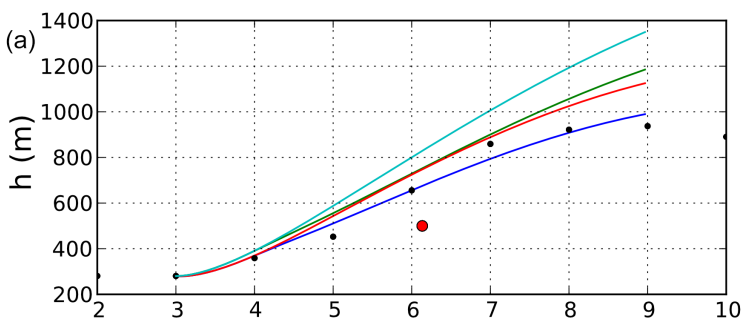

(b)
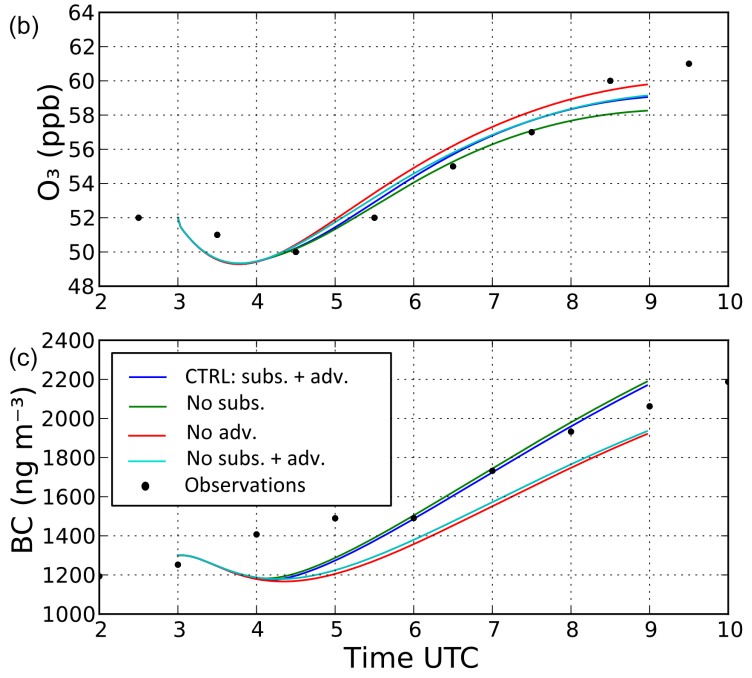

Figure 9. Diurnal variations in MXL/MESSy simulated (a) boundary layer height, (b) surface ozone, and (c) Black Carbon (BC) on 15 March 2012 for four different simulations. The CTRL simulation includes both subsidence and advection of cool and moist air. In the no subs. simulation subsidence is turned off, in the no adv. simulation advection is turned off, and in the no subs. + adv. simulation both subsidence and advection are turned off. In each panel, the black dots show observations made at the surface. In addition, the red dot in the upper panel shows the boundary layer height from a radiosonde measurement.

ent in ozone mixing ratios across the LBL-free troposphere interface, which makes sure that entrainment of air from the free troposphere only dilutes the LBL ozone concentrations by a small fraction.

Unfortunately vertical profiles of black carbon are not available over Nainital site, and therefore measurements at another high-altitude site Hanle $\left(78.96^{\circ} \mathrm{E}, 32.78^{\circ} \mathrm{N}\right.$; $\sim 4.5 \mathrm{~km}$ above sea level) in the Himalayan region were used to estimate the vertical gradient of BC. Average BC concentrations are reported to be $110 \mathrm{ng} \mathrm{m}^{-3}$ at Hanle as compared to $1340 \mathrm{ng} \mathrm{m}^{-3}$ for our site ( $2 \mathrm{~km}$ above sea level) during spring (Dumka et al., 2010; Babu et al., 2011). The measurements show that $\mathrm{BC}$ concentrations increase during the day, which is attributed to the upward mixing of air masses from the nearby valley in the polluted Indo-Gangetic plain region (e. g. Dumka et al., 2010). This leads to a net increase in $\mathrm{BC}$ concentration during daytime, although entrainment of BC-poor free tropospheric air is also active. Emissions of $\mathrm{BC}$ were initially set at their values in the nearby valley, which were in the order of $10^{-12} \mathrm{~kg} \mathrm{~m}^{-2} \mathrm{~s}^{-1}$, based on HTAP inventory (Janssens-Maenhout et al., 2015). The emissions were then tuned to obtain the best comparison with the observations and we found that a sinusoidal emission profile with a maximum of $5.5 \times 10^{-12} \mathrm{~kg} \mathrm{~m}^{-2} \mathrm{~s}^{-1}$ gave the best results.

Modeled BC concentrations are more sensitive to the variations in boundary layer height than those of ozone, because of a larger vertical concentration gradient. BC concentrations are simulated to be lower by $\sim 300 \mathrm{ng} \mathrm{m}^{-3}$ in the case when the boundary layer height is $\sim 350 \mathrm{~m}$ higher, due to missing effects of subsidence and advection. Note that with advection, we only mean advection of cool and moist air, and not advection of BC. The cool and moist air leads to a decrease of the BL temperature and an increase of the humidity. Consequently, the potential temperature and specific humidity gradient between the BL and the free troposphere increase, and therefore entrainment decreases (Janssen et al., 2013). For the same $\mathrm{BC}$ emissions, this means that more BC is trapped in a shallower BL and that it is diluted less with BC-poor air from the free troposphere. Subsidence acts to oppress the BL growth, but enhances entrainment (Janssen et al., 2013). Therefore, the $\mathrm{BC}$ concentration is diluted a little less in the simulation without subsidence.

Besides subsidence and advection, the conditions in the free troposphere can affect the BL dynamics as well. Therefore, the effect of boundary layer variations on BC at Nainital are further explored by conducting simulations for different gradients of potential temperature from boundary layer to free troposphere and for different lapse rates of the potential temperature in the free troposphere (Fig. 10). Initial mixing ratio and surface emission fluxes are given in Table 4 . We find that when the initial potential temperature gradient $\left(\Delta \theta_{0}\right)$ is increased from 0.2 to $2.0 \mathrm{~K}$, the BL growth is suppressed in the first hours of the simulation. Consequently, the BC emissions are concentrated in a shallower BL and therefore overestimated compared to the observations by $350 \mathrm{ng} \mathrm{m}^{-3}$ (maximum). However, during the course of the day, the initial temperature barrier is overcome and the effect on the simulated $\mathrm{BC}$ concentration is reduced to $200 \mathrm{ng} \mathrm{m}^{-3}$ at 09:00 UTC. Finally, the potential temperature lapse rate $\left(\gamma_{\theta}\right)$ determines the growth rate of the BL: if it is small, the potential temperature difference between BL and free troposphere grows less with increasing BL height than when it is large. When $\gamma_{\theta}$ is set to $0.002 \mathrm{~K} \mathrm{~m}^{-1}$ instead of $0.0065 \mathrm{~K} \mathrm{~m}^{-1}$, as in the control experiment, the BL growth is much stronger and the BL height reaches $1650 \mathrm{~m}$ at 09:00 UTC, which is an overestimation of about $700 \mathrm{~m}$, and comparable to the overestimation by WRF. Consequently, BC concentrations are diluted much more and are underestimated by up to $700 \mathrm{ng} \mathrm{m}^{-3}$. For a $\gamma_{\theta}$ of $0.009 \mathrm{~K} \mathrm{~m}^{-1}$, the BL height is underestimated by about $150 \mathrm{~m}$ at maximum. The resulting error in the $\mathrm{BC}$ concentration compared to the control experiment is $300 \mathrm{ng} \mathrm{m}^{-3}$. 
Table 4. Initial mixing ratio in ABL and FT, and surface emission fluxes of the reactants for MXL/MESSy runs. Species in the reaction mechanism that are not included in this table have an initial concentration of zero and no surface emissions. For $\mathrm{O}_{2}$ and $\mathrm{N}_{2}$ we have imposed the values $2 \times 10^{8}$ and $8 \times 10^{8} \mathrm{ppb}$, respectively.

\begin{tabular}{llllllll}
\hline & $\mathrm{O}_{3}$ & $\mathrm{NO}$ & $\mathrm{NO}_{2}$ & $\mathrm{BC}$ & $\mathrm{CH}_{4}$ & $\mathrm{CO}$ & $\mathrm{CO}_{2}$ \\
\hline Initial mixing ratio $(\mathrm{ppb})$ & & & & $\left(\mathrm{ng} \mathrm{m}^{-3}\right)$ & & & \\
ABL & 52 & 1.0 & 0.5 & 1300 & 1724 & 150 & 1300 \\
FT & 57 & 1.0 & 0.5 & 110 & 1724 & 150 & 110 \\
Surface emission flux & $-0.55 \mathrm{ppb} \mathrm{m} \mathrm{s}^{-1}$ & & & $5.5 \times 10^{-3} \mathrm{ng} \mathrm{m}^{-2} \mathrm{~h}^{-1}$ & & & \\
\hline
\end{tabular}
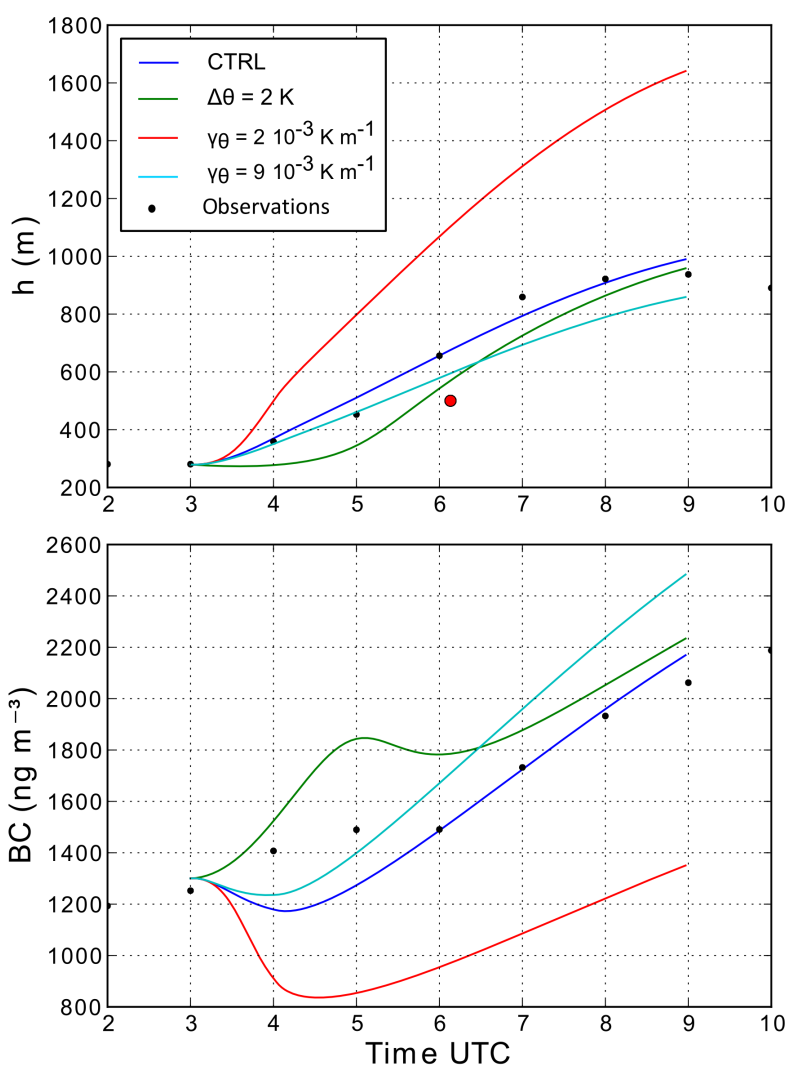

Figure 10. Sensitivity simulations of MXL simulated black carbon variations with different boundary layer dynamics. The blue line shows the control experiment (CTRL), the green line a simulation with the initial potential temperature jump $\left(\Delta \theta_{0}\right)$ set to $2 \mathrm{~K}$, the red line a simulation with a free tropospheric potential temperature lapse rate $\left(\gamma_{\theta}\right)$ set to $0.002 \mathrm{~K} \mathrm{~m}^{-1}$ and the turquoise line a simulation with $\gamma_{\theta}$ set to $0.009 \mathrm{~K} \mathrm{~m}^{-1}$. In each panel, the black dots show observations made at the surface. In the top panel, the red dot shows the boundary layer height from a radiosonde measurement.

Our analysis suggests that an overestimation of boundary layer height has a minor effect on ozone concentrations (of less than $2 \mathrm{ppb}$ ), but a significant effect on $\mathrm{BC}$ concentrations (of $\sim 300$ up to $700 \mathrm{ng} \mathrm{m}^{-3}$ ). The effect of an overestimation of BL height on the concentration of a species is highly dependent on the vertical gradients of the species above our site. Ozone has almost equal concentrations in the BL and free troposphere above Nainital, but black carbon has sharp gradients above $2 \mathrm{~km}$. We suggest that effects of boundary layer dynamics could be much higher in the nearby Gangetic basin, where the gradients will be much steeper due to strong surface sources and intense local photochemistry. More simultaneous measurements of boundary layer dynamics and trace species are highly desirable in the northern Indian region to understand the extent up to which boundary layer dynamics influences the air quality.

\section{Summary and conclusions}

We presented the continuous measurements of ML height over a mountain peak in the central Himalayas from November 2011 to March 2012, obtained through state of the art instrumentation employed as a part of the GVAX intensive field campaign. RWP measurements of $S / N$ are utilized for the first time over the central Himalayas to estimate mixing and boundary layer height and covered the mixing depth variations during late-autumn, complete winter and early spring. The criterion of $S / N>6 \mathrm{~dB}$ for identifying ML depth was found to be adequate, and yielded a reasonable comparison boundary layer height derived from the inversion in specific humidity profiles obtained from radiosonde launches. The results show that the LBL over the site undergoes clear diurnal variations in all months from November to February, attaining peak heights between 07:00 to 08:00 UTC and remaining stable during the night, having minimum height (18:00 to 01:00 UTC). However, in the month of March the LBL continues to decrease in depth till 13:30 UTC (falling up to $500 \mathrm{~m}$ ) and afterwards rises again and remains stable at $650 \mathrm{~m}$ from 14:00 to 22:00 UTC. The strikingly larger depth of the LBL can be attributed to the strong winds over the site during the night, which results in strong orographic lifting over the site. The study re-establishes the fact that RWP gives the better temporal estimation of ML heights compared to balloon borne and other such measurements. As RWP provides the volume scattering from the turbulent scales to which radar is sensitive and receives backscatter power over a larger aperture that provides insight into the LBL dynamics through continuous measurements with fine vertical resolution. 
The observations are further utilized to evaluate high resolution simulations from a regional model (WRF). WRFsimulated day-to-day variations in the noontime boundary layer height were in reasonable agreement with the RWP observations $\left(r^{2}=0.5\right)$. Additionally, the monthly average diurnal variations in boundary layer height from model and observations are generally within the 1-standard deviation variability. The mean biases in the daytime boundary layer height are estimated to be -7 to $+30 \%$ from November to February, but a large overestimation of $\sim 76 \%$ was seen towards the early spring (March). Our study fills a gap by providing a continuous observational data set on the boundary layer dynamics over a geographically complex and environmentally important region of the central Himalayas. We found that while the regional model simulates the boundary layer evolution well during the post-monsoon season and winter, it shows large biases towards spring. This highlights the need to extend boundary layer observations to entire seasons of spring and summer.

Sensitivity simulations using MXL/MESSy were conducted to assess the impact of the uncertainty in ML height on air quality simulations, thereby providing insight in the influence of subsidence and advection processes on boundary layer dynamics over the site. We analyzed effects on two chemical tracers: ozone and black carbon. We find a relatively small effect ( $\sim 2 \mathrm{ppb})$ of overestimated boundary layer height during March on surface ozone concentrations at Nainital. In contrast, significant dilution was found in case of black carbon (by $300-700 \mathrm{ng} \mathrm{m}^{-3}$ ), due to the overestimation of boundary layer height.

It should be noted that spring is a period of strong winds near the surface, maximum solar radiation and the highest pollution loading over this region, which is followed by torrential rains of the monsoon season. Since regional photochemistry and convective mixing are intensified during spring over the Gangetic basin, we suggest that year long measurements with instrumentation such as RWP are highly desirable to understand the influence of boundary layer dynamics on the mixing of pollution.

\section{Data availability}

The observational data used in the study is available freely (see Kotamarthi, 2013 and http://www.arm.gov/sites/amf/ $\mathrm{pgh} /$ instruments).

The Supplement related to this article is available online at doi:10.5194/acp-16-10559-2016-supplement.
Acknowledgements. The RWP, radiosonde and surface observations were carried out as a part of GVAX campaign in joint collaboration among Atmospheric Radiation Measurement (ARM), Department of Energy (US), Indian institute of Science (IISC) and Indian Space Research Organization (ISRO), India. We are thankful to R. L. Coulter for taking care of technical aspects of the RWP measurements. Use of NCEP FNL reanalysis data as input to WRF model is acknowledged. We thank Director, ARIES for providing the necessary support. Raman Solanki is thankful to the Indian Space Research Organization for sponsoring fellowship for his $\mathrm{PhD}$ research work under ABLN\&C: NOBLE project. WRF simulations were performed on the Dresden cluster at the MPI-C. Narendra Ojha and Andrea Pozzer thank Martin Körfer for his help with computing and data storage.

Edited by: E. Weingartner

Reviewed by: two anonymous referees

\section{References}

Angevine, W., White, A., and Avery, S.: Boundary-layer depth and entrainment zone characterization with a boundary-layer profiler, Bound.-Lay. Meteorol., 68, 375-385, 1994.

Babu, S. S., Chaubey, J. P., Krishna Moorthy, K., Gogoi, M. M., Kompalli, S. K., Sreekanth, V., Bagare, P S., Bhatt, B. S., Gaur, V. K., Prabhu, T. P., and Singh, S. N.: High altitude $(\sim 4520$ ma.m.s.l. $)$ measurements of black carbon aerosols over western trans-Himalayas: Seasonal heterogeneity and source apportionment, J. Geophys. Res., 116, D24201, doi:10.1029/2011JD016722, 2011.

Basha, G. and Ratnam, M. V.: Identification of atmospheric boundary layer height over a tropical station using high-resolution radiosonde refractivity profiles: comparison with GPS radio occultation measurements, J. Geophys. Res., 114, D16101, doi:10.1029/2008JD011692, 2009.

Chen, F. and Dudhia, J.: Coupling and advanced land surface hydrology model with the Penn State-NCAR MM5 modeling system, Part I: Model implementation and sensitivity, Mon. Weather Rev., 129, 569-585, 2001.

Chou, M. D. and Suarez, M. J.: An efficient thermal infrared radiation parameterization for use in general circulation models, NASA Tech. Memo., NASA-Goddard Space Flight Center, Greenbelt, MD, USA, 104606, 85 pp., 1994.

Coulter, R. L. and Holdridge, D. H.: A procedure for the automatic estimation of mixed layer height, Proc. Eighth Atmospheric Radiation Measurement (ARM) Program Science Team Meeting, 24-26 March 1998, Tucson, AZ, USA, Department of Energy Office of Energy Research, 177-180, 1998.

De Wekker, S. F. J. and Kossmann, M.: Convective Boundary Layer Heights Over Mountainous Terrain - A Review of Concepts, Front. Earth Sci., 3, 77, doi:10.3389/feart.2015.00077, 2015.

Dumka, U. C., Krishna Moorthy, K., Kumar, R., Hegde, P., Sagar, R., Pant, P., Singh, N., and Suresh Babu, S.: Characteristics of aerosol black carbon mass concentration over a high altitude location in the Central Himalayas from multi-year measurements, Atmos. Res., 96, 510-521, doi:10.1016/j.atmosres.2009.12.010, 2010 . 
Friehe, C. A.: Review of atmospheric boundary layer research, 1983-1986, Rev. Geophys., 25, 387-392, doi:10.1029/RG025i003p00387, 1987.

Gage, K. S.: Radar observations of the free atmosphere: Structure and dynamics, in: Radar in Meteorology, edited by: Atlas, D., Amer. Meteor. Soc., Boston, USA, 534-565, 1990.

Garratt, J. R.: Sensitivity of climate simulations to landsurface and atmospheric boundary-layer treatments A review, J. Climate, 6, 419-448, doi:10.1175/15200442(1993)006<0419:SOCSTL>2.0.CO;2, 1993.

Garratt, J. R. and Taylor, P. A.: Boundary-Layer Meteorology 25th Anniversary Volume, 1970-1995: Invited Reviews and Selected Contributions to Recognise Ted Munn's Contribution as Editor over the Past 25 Years, Springer Netherlands, 417 pp., doi:10.1007/978-94-017-0944-6, 1996.

Gautam, R., Hsu, N. C., Kafatos, M., and Tsay, S. C.: Influences of winter haze on fog/low cloud over the Indo-Gangetic plains, J. Geophys. Res., 112, D05207, doi:10.1029/2005JD007036, 2007.

Gossard, E. E., Chadwick, R. B., Neff, W. D., and Moran, K. P.: Use of Ground-Based Doppler Radars to Measure Gradients, Fluxes and Structure Parameters in Elevated Layers, J. Appl. Meteorol., 21, 211-226, 1982.

Green, J. L., Gage, K. S., and vanZandt, T. E.: Atmospheric measurements by VHF pulsed Doppler radar, IEEE T. Geosci. Elect., GE-17, 262-280, 1979.

Henne, S., Furger, M., Nyeki, S., Steinbacher, M., Neininger, B., de Wekker, S. F. J., Dommen, J., Spichtinger, N., Stohl, A., and Prévôt, A. S. H.: Quantification of topographic venting of boundary layer air to the free troposphere, Atmos. Chem. Phys., 4, 497509, doi:10.5194/acp-4-497-2004, 2004.

Hooper, W. P. and Eloranta, E.: Lidar measurements of wind in the planetary boundary layer: the method, accuracy and results from joint measurements with radiosonde and kytoon, J. Clim. Appl. Meteorol., 25, 990-1001, 1986.

Janjic, Z. I.: The surface layer in the NCEP Eta Model, Eleventh Conference on Numerical Weather Prediction, Norfolk, VA, USA, 19-23 August 1996, Amer. Meteor. Soc., Boston, MA, USA, 354-355, 1996.

Janjic, Z. I.: Nonsingular Implementation of the Mellor-Yamada Level 2.5 Scheme in the NCEP Meso model, NCEP Office Note, 437, 61 pp., available at: http://www.emc.ncep.noaa.gov/ officenotes/newernotes/on437.pdf (last access: 17 August 2016), 2002

Janssen, R. H. H. and Pozzer, A.: Description and implementation of a MiXed Layer model (MXL, v1.0) for the dynamics of the atmospheric boundary layer in the Modular Earth Submodel System (MESSy), Geosci. Model Dev., 8, 453-471, doi:10.5194/gmd-8-453-2015, 2015.

Janssen, R. H. H., Vilà-Guerau de Arellano, J., Jimenez, J. L., Ganzeveld, L. N., Robinson, N. H., Allan, J. D., Coe, H., and Pugh, T. A. M.: Influence of boundary layer dynamics and isoprene chemistry on the organic aerosol budget in a tropical forest, J. Geophys. Res.-Atmos., 118, 9351-9366, 2013.

Janssens-Maenhout, G., Crippa, M., Guizzardi, D., Dentener, F., Muntean, M., Pouliot, G., Keating, T., Zhang, Q., Kurokawa, J., Wankmüller, R., Denier van der Gon, H., Kuenen, J. J. P., Klimont, Z., Frost, G., Darras, S., Koffi, B., and Li, M.: HTAP_v2.2: a mosaic of regional and global emission grid maps for 2008 and 2010 to study hemispheric transport of air pollu- tion, Atmos. Chem. Phys., 15, 11411-11432, doi:10.5194/acp15-11411-2015, 2015.

Jöckel, P., Kerkweg, A., Pozzer, A., Sander, R., Tost, H., Riede, H., Baumgaertner, A., Gromov, S., and Kern, B.: Development cycle 2 of the Modular Earth Submodel System (MESSy2), Geosci. Model Dev., 3, 717-752, doi:10.5194/gmd-3-717-2010, 2010.

Kalapureddy, M. C. R., Kishore Kumar, K., Sivakumar, V., Ghosh, A. K., Jain, A. R., and Krishna Reddy, K.: Diurnal and seasonal variability of TKE dissipation rate in the ABL over a tropical station using UHF wind profiler, J. Atmos. Solar-Terr. Phy., 69, 419-430, 2007.

Ketterer, C., Zieger, P., Bukowiecki, N., Collaud Coen, M., Maier, O., Ruffieux, D., and Weingartner, E.: Investigation of the planetary boundary layer in the Swiss Alps using remote sensing and in-situ measurements, Bound.-Lay. Meteorol., 151, 317334, doi:10.1007/s10546-013-9897-8, 2014.

Kossmann, M., Vögtlin, R., Corsmeier, U., Vogel, B., Fiedler, F., Binder, H. J., Kalthoff, N., and Beyrich, F.: Aspects of the convective boundary layer structure over complex terrain, Atmos. Environ., 32, 1323-1348, doi:10.1016/S1352-2310(97)00271-9, 1998.

Kotamarthi, V. R.: Ganges Valley Aerosol Experiment: Science and Operations Plan, DOE/SC-ARM-10-019, available at: http://www.arm.gov/publications/programdocs/ doe-sc-arm-10-019.pdf?id=25 (last access: 10 August 2016), 2010.

Kotamarthi, V. R.: Ganges Valley Aerosol Experiment (GVAX) Final Campaign Report, DOE/SC-ARM-14-011, available at: https://www.arm.gov/publications/programdocs/ doe-sc-arm-14-011.pdf (last access: 17 August 2016), 2013.

Kotamarthi, V. R. and Satheesh, S. K.: Ganges Valley Aerosol Experiment, Air \& Waste Management Association, Em, The magazine for environmental managers, available at: http://pubs.awma. org/gsearch/em/2011/8/kotamarthi.pdf (last access: 10 August 2016), 2011.

Kumar, R., Naja, M., Pfister, G. G., Barth, M. C., and Brasseur, G. P.: Simulations over South Asia using the Weather Research and Forecasting model with Chemistry (WRF-Chem): set-up and meteorological evaluation, Geosci. Model Dev., 5, 321-343, doi:10.5194/gmd-5-321-2012, 2012a.

Kumar, R., Naja, M., Pfister, G. G., Barth, M. C., Wiedinmyer, C., and Brasseur, G. P.: Simulations over South Asia using the Weather Research and Forecasting model with Chemistry (WRFChem): chemistry evaluation and initial results, Geosci. Model Dev., 5, 619-648, doi:10.5194/gmd-5-619-2012, 2012b.

Manoharan, V. S., Kotamarthi, R., Feng, Y., and Cadeddu, M. P.: Increased absorption by coarse aerosol particles over the Gangetic-Himalayan region, Atmos. Chem. Phys., 14, 11591165, doi:10.5194/acp-14-1159-2014, 2014.

Mlawer, E. J., Taubman, S. J., Brown, P. D., Iacono, M. J., and Clough, S. A.: Radiative transfer for inhomogeneous atmospheres: RRTM, a validated correlated-k model for the longwave, J. Geophys. Res.-Atmos., 102, 16663-16682, doi:10.1029/97JD00237, 1997.

Ojha, N., Naja, M., Singh, K. P., Sarangi, T., Kumar, R., Lal, S., Lawrence, M. G., Butler, T. M., and Chandola, H. C.: Variabilities in ozone at a semi-urban site in the Indo-Gangetic Plain region: Association with the meteorology and regional processes, 
J. Geophys. Res., 117, D20301, doi:10.1029/2012JD017716, 2012.

Ojha, N., Naja, M., Sarangi, T., Kumar, R., Bhardwaj, P., Lal, S., Venkataramani, S., Sagar, R., Kumar, A., and Chandola, H. C.: On the Processes Influencing the Vertical distribution of ozone over the central Himalayas: Analysis of Yearlong ozonesonde observations, Atmos. Environ., 88, 201-211, doi:10.1016/j.atmosenv.2014.01.031, 2014.

Ojha, N., Pozzer, A., Rauthe-Schöch, A., Baker, A. K., Yoon, J., Brenninkmeijer, C. A. M., and Lelieveld, J.: Ozone and carbon monoxide over India during the summer monsoon: regional emissions and transport, Atmos. Chem. Phys., 16, 3013-3032, doi:10.5194/acp-16-3013-2016, 2016.

Ottersten, H.: Atmospheric Structure and Radar Backscattering in Clear Air, Radio Sci. 4, 1179-1193, 1969.

Raghavan, S.: Radar Meteorology, Springer, New York, USA, 2003.

Reddy, K. K., Kozu, T., Ohno, Y., Nakamura, K., Higuchi, A., Madhu Chandra Reddy, K., Anandan, V. K., Srinivasulu, P., Jain, A. R., Rao, P. B., Ranga Rao, R., Viswanathan, G., and Narayana Rao, D.: Planetary boundary layer and precipitation studies using lower atmospheric wind profiler over tropical India, Radio Sci., 37, 14-1-14-21, doi:10.1029/2000RS002538, 2002.

Reddy, K. K., Kozu, T., and Rao D. N.: Wind profiler radar for understanding the tropical convective boundary layer during different seasons, Indian J. Radio Space, 35, 105-115, 2006.

Reddy, K. K., Naja, M., Ojha, N., Mahesh, P., and Lal, S.: Influences of the boundary layer evolution on surface ozone variations at a tropical rural site in India, J. Earth Syst. Sci., 121, 911-922, 2012.

Sagar, R., Kumar, B., Dumka, U. C., Moorthy, K. K., and Pant, P.: Characteristics of aerosol spectral optical depths over Manora Peak: A high-altitude station in the central Himalayas, J. Geophys. Res., 109, D06207, doi:10.1029/2003JD003954, 2004.

Sagar, R., Dumka, U. C., Naja, M., Singh, N., and Phanikumar, D. V.: ARIES, Nainital: a strategically important location for climate change studies in the Central Gangetic Himalayan region, Curr. Sci. India, 109, 703-715, 2015.

Sarangi, T., Naja, M., Ojha, N., Kumar, R., Lal, S., Venkataramani, S., Kumar, A., Sagar, R., and Chandola, H. C.: First simultaneous measurements of ozone, $\mathrm{CO}$ and $\mathrm{NO}_{y}$ at a high altitude regional representative site in the central Himalayas, J. Geophys. Res., 119, 1592-1611, doi:10.1002/2013JD020631, 2014.

Simpson, M., Raman, S., Lundquist, J. K., and Leach, M.: A study of the variation of urban mixed layer heights, Atmos. Environ., 41, 6923-6930, 2007.

Singh, N., Joshi, R. R., Chun, H.-Y., Pant, G. B., Damle, S. H., and Vashishtha, R. D.: Seasonal, annual and inter-annual features of turbulence parameters over the tropical station Pune $\left(18^{\circ} 32^{\prime} \mathrm{N}\right.$, $73^{\circ} 51^{\prime}$ E) observed with UHF wind profiler, Ann. Geophys., 26, 3677-3692, doi:10.5194/angeo-26-3677-2008, 2008.

Solanki, R. and Singh, N.: LiDAR observations of the vertical distribution of aerosols in free troposphere: Comparison with CALIPSO level-2 data over the central Himalayas, Atmos. Environ., 99, 227-238, 2014.
Solanki, R., Singh, N., Pant, P., Dumka, U. C., Kumar, Y. B., Srivastava, A. K., Bist, S., and Chandola, H. C.: Detection of long range transport of aerosols with elevated layers over high altitude station in the central Himalayas: A case study on 22 and 24 March 2012 at ARIES, Nainital, Indian J. Radio Space, 42, 232-239, 2013.

Solanki, R., Singh, N., Kiran Kumar, N. V. P., Rajeev, K., and Dhaka, S. K.: Time variability of surface-layer characteristics over a mountain ridge in the central Himalayas during the spring season, Bound.-Lay. Meteorol., 158, 453-471, doi:10.1007/s10546-015-0098-5, 2016.

Stull, R. B.: An Introduction to Boundary Layer Meteorology, Kluwer Academic Publishers, Boston, MA, USA, 1989.

Taraborrelli, D., Lawrence, M. G., Butler, T. M., Sander, R., and Lelieveld, J.: Mainz Isoprene Mechanism 2 (MIM2): an isoprene oxidation mechanism for regional and global atmospheric modelling, Atmos. Chem. Phys., 9, 2751-2777, doi:10.5194/acp-92751-2009, 2009.

Tatarskii, V. I.: The Effects of the Turbulent Atmosphere on Wave Propagation, Translated from Russian, Isr. Program for Sci. Transl., Jerusalem, 472 pp., available as TT-68-50464/XAB, Natl. Tech. Inf. Serv., Springfield, Va., USA, 1971.

Thompson, G., Field, P. R., Rasmussen, R. M., and Hall, W. D.: Explicit forecasts of winter precipitation using an improved bulk microphysics scheme. part II: implementation of a new snow parameterization, Mon. Weather Rev., 136, 5095-5115, doi:10.1175/2008MWR2387.1, 2008.

Vilà-Guerau de Arellano, J., van Heerwaarden, C. C., van Stratum, B. J., and van den Dries, K.: Atmospheric boundary layer: Integrating chemistry and land interactions, Cambridge University Press, New York, USA, 265 pp., 2015.

White, A. B., Fairall, C. W., and Thompson, D. W.: Radar Observations of Humidity Variability In and Above the Marine Atmospheric Boundary Layer, J. Atmos. Ocean. Tech. 8, 639-558, 1991a.

White, A. B., Fairall, C. W., and Wolfe, D. E.: Use of $915 \mathrm{MHz}$ Wind Profiler Data to Describe Diurnal Variability of the Mixed Layer, in: Preprints, 7th Joint Conference on Applications of Air Pollution Meteorology with AWMA, New Orleans, USA, 1418 January 1991, Amer. MeteoroI. Soc., pp. J161-J166, 1991 b.

Xie, B., Fung, J. C. H., Chan, A., and Lau, A.: Evaluation of nonlocal and local planetary boundary layer schemes in the WRF model, J. Geophys. Res., 117, D12103, doi:10.1029/2011JD017080, 2012.

Xie, F., Wu, D. L., Ao, C. O., Mannucci, A. J., and Kursinski, E. R.: Advances and limitations of atmospheric boundary layer observations with GPS occultation over southeast Pacific Ocean, Atmos. Chem. Phys., 12, 903-918, doi:10.5194/acp-12-903-2012, 2012. 